Article

\title{
Oral Cancer Knowledge, Attitude, and Practice of Dentists in the State of Qatar
}

\author{
Diana H. Jboor ${ }^{1}\left(\mathbb{D}\right.$, Mohammed S. Al-Darwish ${ }^{2}$ and Ula Nur ${ }^{1, *}$ \\ 1 Department of Public Health, College of Health Sciences, QU Health, Qatar University, Doha 2713, Qatar; \\ dj1600061@student.qu.edu.qa \\ 2 Hamad dental Center, Hamad Medical Corporation, Doha 3050, Qatar; maldarwish@hamad.qa \\ * Correspondence: ula.nur@qu.edu.qa
}

Received: 11 February 2019; Accepted: 28 March 2019; Published: 11 April 2019

\begin{abstract}
Objectives: The aim of this study was to assess existing knowledge on oral cancer (OC), attitude toward OC examination, and clinical practice among dentists practicing in the governmental health sector in the State of Qatar, including the influence of personal characteristics. Materials and Methods: All 271 dentists practicing in Primary Health Care Centers (PHCC) and the Hamad Medical Corporation (HMC) were invited to participate in this cross-sectional study. Of these, 177 completed a self-administered, 48-item questionnaire. Based on the responses, knowledge of the risk factors for and clinical presentation of OC was categorized as high, medium, or low, and then further separated into satisfactory (medium/high) and unsatisfactory (low). Information on attitudes toward OC examination and clinical practice was also taken from the questionnaire. Results: The mean score for knowledge of the clinical presentation of OC was 7.59 (standard deviation $[S D]=2.40)$ out of 14 . The mean score for knowledge of the risk factors for OC was $8.96(\mathrm{SD}=2.31)$ out of 16. Dentists with $\leq 10$ years of experience were more likely to have satisfactory knowledge of OC compared to dentists with $>15$ years of experience. Attending a continuous professional development (CPD) course on OC showed a trend with satisfactory clinical knowledge, although it was not statistically significant. Conclusion: This study identified gaps in dentists' knowledge of OC; dentists demonstrated unsatisfactory knowledge of the clinical presentation of and risk factors for OC. The findings highlighted the need for educational interventions on OC, which are essential to improving health care outcomes and delivery of care.
\end{abstract}

Keywords: oral cancer; knowledge; attitude; practice; dentists; Qatar; continuous professional development courses

\section{Introduction}

Oral cancer (OC) is the 15th most commonly diagnosed cancer worldwide and accounts for $2.1 \%$ of all cancers [1]. OC is a silent, invasive disease, which usually presents as a persistent, painless ulcer on the side of the tongue, or an intra-oral, red lesion without any disturbing symptoms. These signs are usually neglected by the patient and are sometimes unnoticed by dentists. The prognosis of OC depends on age, the general health of the patient, the type and location of the lesion, and the response to treatment [2]. Although there is limited evidence about the effectiveness of population-based visual screening on OC mortality, a reduction in mortality among patients at high-risk for OC has been reported [3]. Despite this limited evidence, it is important that dentists be on the lookout for any suspicious lesions while examining patients.

The incidence rate of OC varies by country due to differences in the distribution of etiological factors. In 2015, in Qatar, head and neck cancers accounted for $4 \%$ of all malignant cancers; about $60 \%$ of these cases were diagnosed in late stages (Qatar National Cancer Registry 2015, personal 
communication, November 2017). In addition, there has been an annual increase in the incidence of OC in the country, which has been linked to rapid population increases in the last decade. The population of Qatar consists of a high proportion of expatriates, and there is an imbalance in sex distribution, with a 3:1 male-to-female ratio [4].

The World Health Organization (WHO) Global Oral Health programs include two approaches to prevent OC: Reduction of exposure to risk factors and early detection through screening [5]; dental professionals play a crucial role in the latter. Several studies have evaluated healthcare professionals' knowledge of OC and their clinical practice regarding OC examination [6-10]. Dentists in Qatar are of different nationalities and from different educational and training backgrounds. The aim of this study was to assess the existing knowledge on OC, and dentists' attitude and clinical practice toward OC examination. In addition, we analyzed associations between oral cancer knowledge and the basic characteristics of dentists practicing in the governmental health sector in the State of Qatar.

\section{Material and Methods}

We invited all 271 dentists practicing in Qatar's 23 Primary Health Care Centers (PHCC), which provide mainly general dental services, and the Hamad Medical Corporation (HMC), which provides a wide range of specialized treatment, to participate in this cross-sectional study. These practice settings were then divided into 5 clusters: PHCC-Northern region, PHCC-Central region, PHCC-Western region, HMC-Hamad Dental Centre, and HMC-Al Wakra Hospital dental clinics. Dentists were invited via their institutional e-mails; invitations included information about the study and encouraged dentists to participate. Non-responders were sent multiple additional invitations in an effort to boost recruitment. Those who chose to participate were asked to complete a structured, self-administered questionnaire (Appendix A), which was written in English. Of the 271 invited dentists, 177 completed and returned the questionnaire and were included in the analysis (response rate $65.31 \%$ ). Completed questionnaires were sealed in envelopes coded with serial numbers to ensure privacy. Consent forms were obtained and included language on the assurance of confidentiality. Ethical approval was obtained from the Institution Review Board of Qatar University, on 11 March 2017 (No: QU-IRB 818-E/17) and from the Institution Review Board of the Primary Health Care Corporation, on 21 January 2018 (No: PHCC/IEC/17/12/043). HMC approval was obtained from Hamad Dental Centre. All participants signed an informed consent form, and confidentiality of all information was ensured by the secure storage of data in a password protected computer.

The questionnaire (Appendix A) consisted of four sections: (1) Personal characteristics, (2) knowledge of the clinical presentation of and risk factors for OC, (3) attitude toward OC examination, and (4) clinical practice regarding OC. There were six items in the personal characteristics' section of the questionnaire. There were 14 items on the knowledge of the clinical presentation of OC and 16 items on the knowledge of risk factors for OC. Participants received 1 point for each correct response and were categorized by the number of correct responses (knowledge of the clinical presentation of OC: 0-9 low, 10-11 medium, 12-14 high; knowledge of the risk factors for OC: 0-8 low, 9-10 medium, 11-16 high) according to a previously developed scale $[7,8]$. This categorization was then further separated into satisfactory (medium/high) and unsatisfactory (low).

The section on attitude toward OC examination consisted of 11 items meant to measure dentists' opinion about their role in OC prevention. Responses were given on 5-point Likert scale ( $1=$ strongly agree, $2=$ agree, $3=$ disagree, $4=$ strongly disagree, $5=$ don't know). The section on clinical practice regarding OC consisted of three items on the appropriate procedure to examine the oral cavity, factors dentists probe when talking to patients about their medical history, and the type of educational materials dentists had available for their patients. Responses to items in the attitude toward OC examination and clinical practice regarding $\mathrm{OC}$ sections of the questionnaire were measured as proportions. All questionnaire items were previously tested for validity and reliability $[6,8]$. 


\section{Statistical Analysis}

Cluster-adjusted analysis was performed to account for the difference in the knowledge scores in the five different practice settings (Figure 1). The intra-class correlation coefficient (ICC) was used to adjust for the impact of a clustering effect on the knowledge of OC. We assessed the impact of personal characteristics (sex, years of practical experience, scope of practice, and last continuous professional development (CPD) course on OC attended) on the knowledge of OC using cluster-adjusted $\mathrm{Chi}^{2}$ and cluster-adjusted logistic regression. The cluster-adjusted $\mathrm{Chi}^{2}[11,12]$ is used for comparing dichotomous scores when the data include intra-cluster correlation. It calculates two adjusted chi-squared values, one based on the effect of clustering pooled across all participants' settings, and one based on the effects of clustering by each setting. This method was applied to evaluate associations between the scores for knowledge of the clinical presentation and risk factors for OC and a number of covariates. Finally, univariate logistic regression, adjusted for the clustering effect, was used to identify potential predictors for satisfactory knowledge versus unsatisfactory knowledge of OC. All statistical analysis was performed using the statistical package, STATA 15 [13].
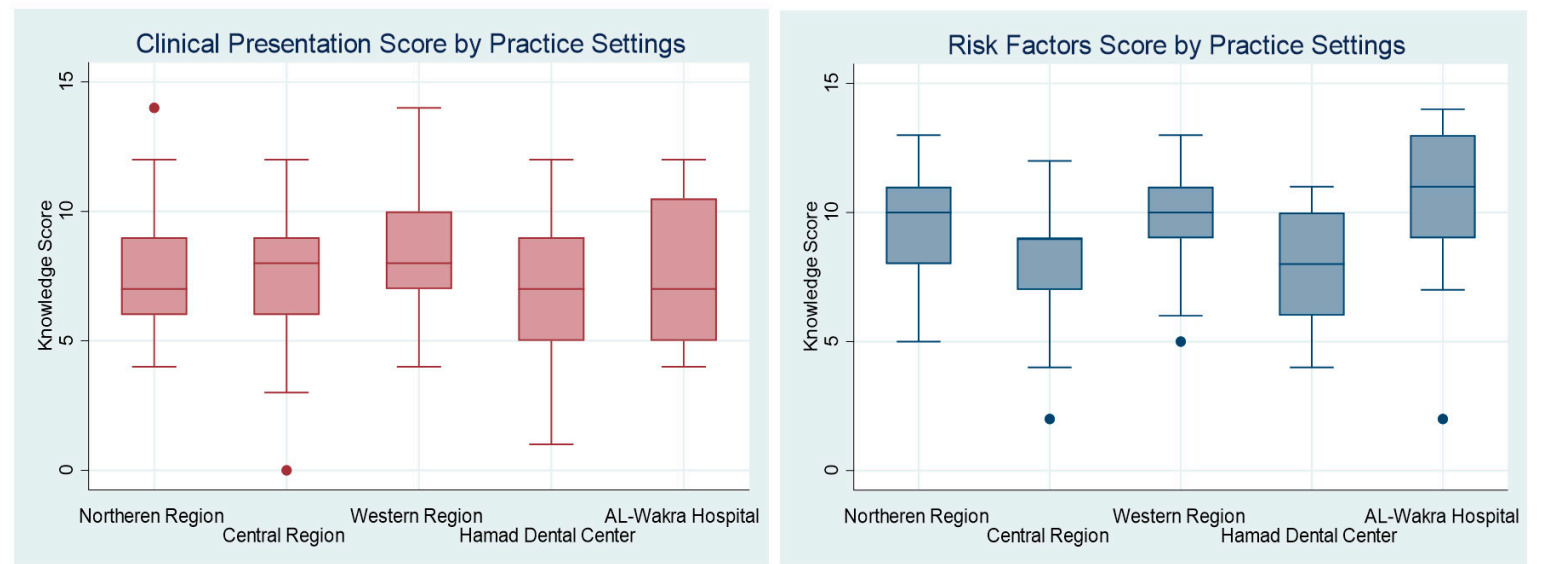

Figure 1. Score for knowledge of the clinical presentation of and risk factors for oral cancer by the five practice settings $(n=177)$.

\section{Results}

\subsection{Personal Characteristics}

Of the 177 participating dentists, almost half were females. A total of 91 dentists (52.3\%) had more than 15 years of practical experience, and just over half $(102,58.6 \%)$ were general practice dentists. Among the respondents, 62 dentists (35\%) had attended a CPD course on OC within the past 2 years (Table 1).

\subsection{Knowledge of the Clinical Presentation of and Risk Factors for Oral Cancer}

The average score for knowledge of the clinical presentation of OC was 7.59 (SD $=2.40$, range: $0-14)$. The majority of dentists could correctly identify proper tongue examination steps $(147,83.1 \%)$ for OC. A high proportion of dentists $(149,84.2 \%)$ correctly replied that squamous cell carcinoma is the most common form of OC, and 138 (77.9\%) and 96 (54.2\%) dentists correctly identified the tongue and the floor of the mouth as the first and second most common sites of OC, respectively. However, only $42.9 \%$ correctly identified both sites. Only $38(21.5 \%)$ dentists replied correctly that early-stage OC is asymptomatic, and $56(31.6 \%)$ dentists correctly replied that the majority of OC is diagnosed in people aged 60 years or older. One hundred and thirty-four $(75.7 \%)$ dentists replied correctly that the lymph nodes are an important site of OC metastasis. OC is diagnosed mainly in advanced stages, but only $69(39 \%)$ dentists were familiar with this. Leukoplakia and erythroplakia are conditions associated 
with OC, and 95 (53.7\%) dentists correctly identified these conditions, but only 44 (24.9\%) were able to define erythroplakia as a more serious premalignant condition than leukoplakia (Table 2).

Table 1. Personal characteristics of the participants.

\begin{tabular}{|c|c|c|}
\hline Characteristics $(n=177)$ & Frequency $(n)$ & $(\%)$ \\
\hline \multicolumn{3}{|l|}{ Practice Setting } \\
\hline HMC & 45 & $25.4 \%$ \\
\hline PHCC & 132 & $74.6 \%$ \\
\hline \multicolumn{3}{|l|}{ Sex } \\
\hline Male & 92 & $51.9 \%$ \\
\hline Female & 85 & $48.1 \%$ \\
\hline \multicolumn{3}{|l|}{ Age (Years) } \\
\hline $23-29$ & 7 & $4.00 \%$ \\
\hline $30-39$ & 83 & $47.4 \%$ \\
\hline $40-49$ & 57 & $32.6 \%$ \\
\hline $50-59$ & 22 & $12.6 \%$ \\
\hline$>60$ & 6 & $3.40 \%$ \\
\hline \multicolumn{3}{|l|}{ Years of Practical Experience } \\
\hline$<5$ years & 4 & $2.30 \%$ \\
\hline $5-10$ years & 31 & $17.8 \%$ \\
\hline $11-15$ years & 48 & $27.6 \%$ \\
\hline$>15$ years & 91 & $52.3 \%$ \\
\hline \multicolumn{3}{|l|}{ Scope of Practice } \\
\hline General Practice & 102 & $58.60 \%$ \\
\hline Specialty Practice & 72 & $41.40 \%$ \\
\hline \multicolumn{3}{|c|}{ Last CPD Course on Oral Cancer Attended } \\
\hline$<2$ years & 62 & $35.0 \%$ \\
\hline $2-5$ years ago & 39 & $22.0 \%$ \\
\hline$>5$ years ago & 50 & $28.3 \%$ \\
\hline Never & 26 & $14.7 \%$ \\
\hline \multicolumn{3}{|l|}{ Practice Setting } \\
\hline Northern Region & 41 & $23.2 \%$ \\
\hline Central region & 45 & $25.4 \%$ \\
\hline Western region & 46 & $26 \%$ \\
\hline Hamad Dental Centre & 33 & $18.6 \%$ \\
\hline AL-Wakra Hospital & 12 & $6.8 \%$ \\
\hline
\end{tabular}

CPD: continuous professional development.

Table 2. Proportion of dentists that correctly identified the clinical presentation of oral cancer.

\begin{tabular}{ccc}
\hline Clinical Presentation Questions $(\boldsymbol{n = 1 7 7 )}$ & Number & $\mathbf{( \% )}$ \\
\hline Correctly identify tongue examination. & 147 & $83.1 \%$ \\
Squamous cell carcinoma is the most common form of oral cancer. & 149 & $84.2 \%$ \\
Tongue is the first most common site of oral cancer. & 138 & $77.9 \%$ \\
Floor of the mouth is the second most common sites of oral cancer. & 96 & $54.2 \%$ \\
Familial clustering is Least likely associated with oral cancer. & 58 & $32.8 \%$ \\
Oral cancer early sign is asymptomatic. & 38 & $21.5 \%$ \\
Majority of oral cancer cases are diagnosed in people 60 years or older. & 56 & $31.6 \%$ \\
Lymph nodes Hard, painless, mobile or fixed. & 134 & $75.7 \%$ \\
Ventral-lateral border of the tongue is site most likely develop oral cancer. & 82 & $46.3 \%$ \\
Oral cancer most often diagnosed in advanced stage. & 69 & $39.0 \%$ \\
Lip cancers are related to sun exposure. & 112 & $63.3 \%$ \\
Early oral cancer lesions appear small, painless, red area. & 118 & $66.7 \%$ \\
Erythroplakia and Leukoplakia are associated with oral cancer. & 95 & $53.7 \%$ \\
Erythroplakia is a more serious premalignant condition than leukoplakia. & 44 & $24.9 \%$ \\
\hline
\end{tabular}


The average score for knowledge of the risk factors for OC was 8.96 ( $\mathrm{SD}=2.31$, range: 2-14). A high percentage of dentists correctly identified older age (72.9\%), alcohol use, (93.2\%), tobacco use $(97.7 \%)$, viral infection $(85.3 \%)$, and prior OC $(94.4 \%)$ as risk factors for OC. Fifty $(28.3 \%)$ dentists correctly identified low consumption of fruits and vegetables as a risk factor for OC. Although 132 dentists $(74.6 \%)$ correctly identified chewing betel quid as a risk factor for OC, $41(23.2 \%)$ did not know of its effect. This was also seen with Gutka use, with 87 dentists $(49.2 \%)$ correctly identifying it as a risk factor and $84(47.5 \%)$ reporting that they did not know of its effect (Figure 2).

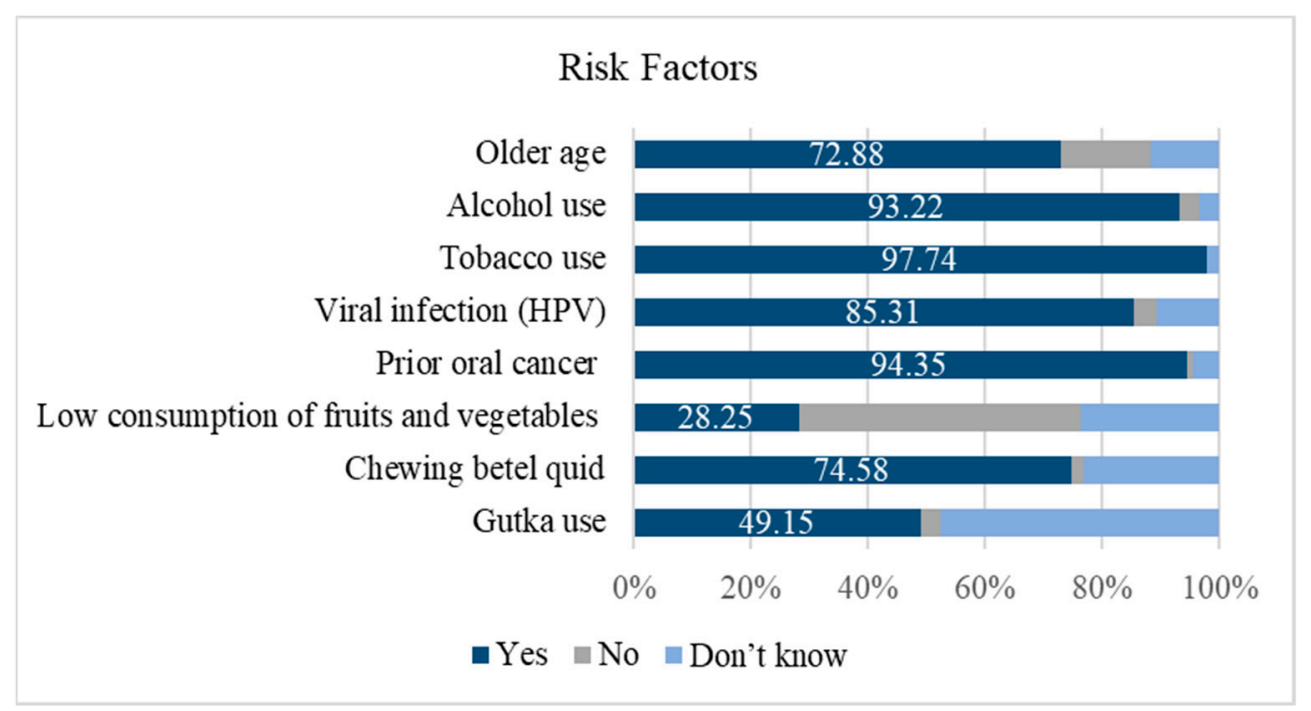

Figure 2. Percentage of dentists that correctly identified the listed risk factors for oral cancer $(n=177)$.

The majority of dentists $(137,77.4 \%)$ correctly identified mouth rinse use as a non-risk factor. However, only a low percentage of dentists correctly replied that spicy food $(29.9 \%)$ and poor oral hygiene (31.6\%) are non-risk factors for OC, and only 54 dentists (30.5\%) correctly identified a poor fitting denture as a non-risk factor for OC (Figure 3).

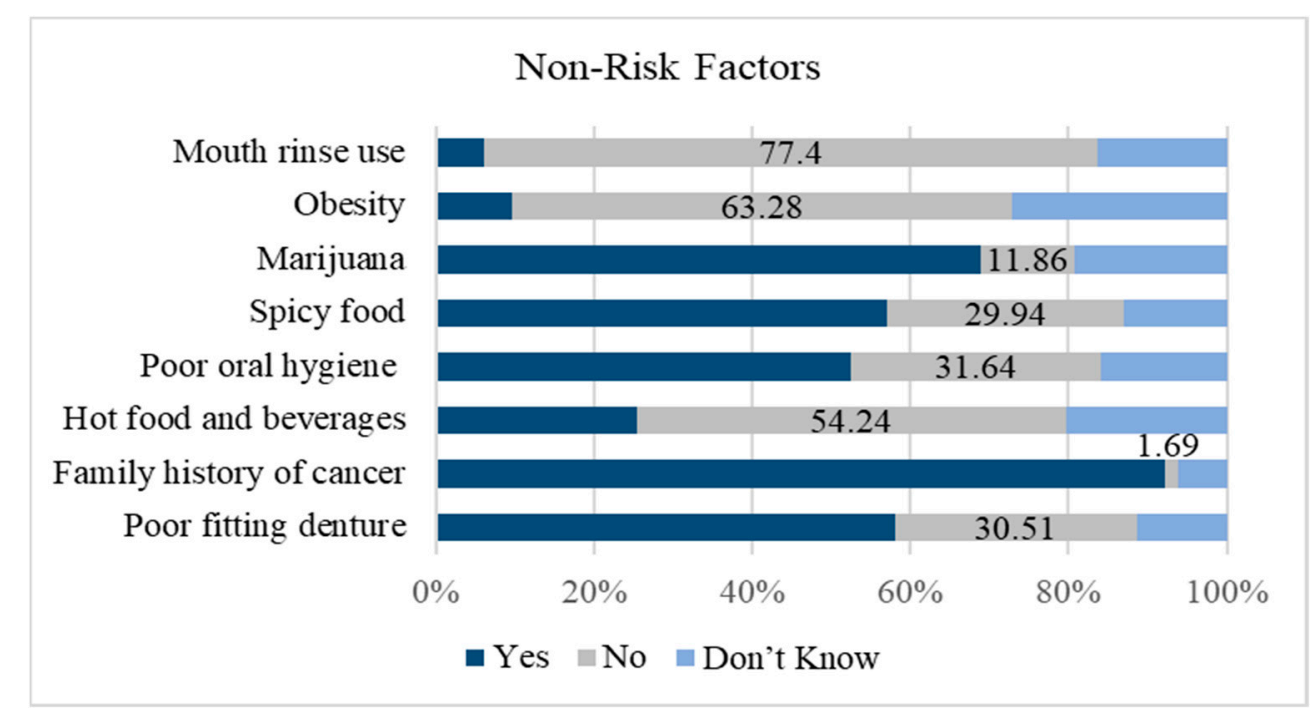

Figure 3. Percentage of dentists that correctly identified the listed non-risk factors for oral cancer $(n=177)$.

To further explore patterns in the distribution of knowledge among dentists, knowledge of the clinical presentation of and risk factors for OC were cross-classified. Only $15.8 \%$ of dentists had satisfactory (medium/high) knowledge for both of these aspects; $30.5 \%$ had unsatisfactory (low) 
knowledge of both aspects. One hundred and thirty-eight dentists (78\%) had unsatisfactory knowledge of the clinical presentation of OC.

\subsection{Attitude Toward Oral Cancer Examination}

Among the respondents, 116 dentists (66.7\%) agreed that their knowledge about OC was current. Also, 86 dentists $(48.6 \%)$ agreed that they were adequately trained to examine patients for OC. The vast majority of dentists $(90 \%)$ agreed that they should be trained to provide tobacco cessation education. Replies regarding dentists' confidence in performing OC examination showed that 69 dentists $(39.4 \%)$ either agreed or strongly agreed that they were not confident in their training. Moreover, $65.5 \%$ strongly agreed that they were comfortable referring patients with suspicious oral lesions to specialists (Figure 4). When respondents were asked about detecting the early signs and symptoms of OC, $80.39 \%$ of general practice dentists and $70.83 \%$ of specialist dentists believed that general practice dentists have the primary role.

My knowledge about oral cancer is current.

I am adequately trained to examine patients for oral cancer.

Dentists should be trained to provide tobacco cessation education.

Early detection improves 5 -year survival rated from oral cancers.

I am comfortable palpating lymph nodes in the necks of patients.

Oral cancer examinations should be a separate reimbursable procedure.

I am not confident in my ability to perform oral cancer exams.

Oral cancer exams can be discontinued after 3 negative exams.

I am comfortable referring patients with suspicious oral lesions to specialists.

Oral cancer examinations for adults 18-39 years of age should be provided annually.

Oral cancer examinations for those 40 years of age and older should be provided annually.

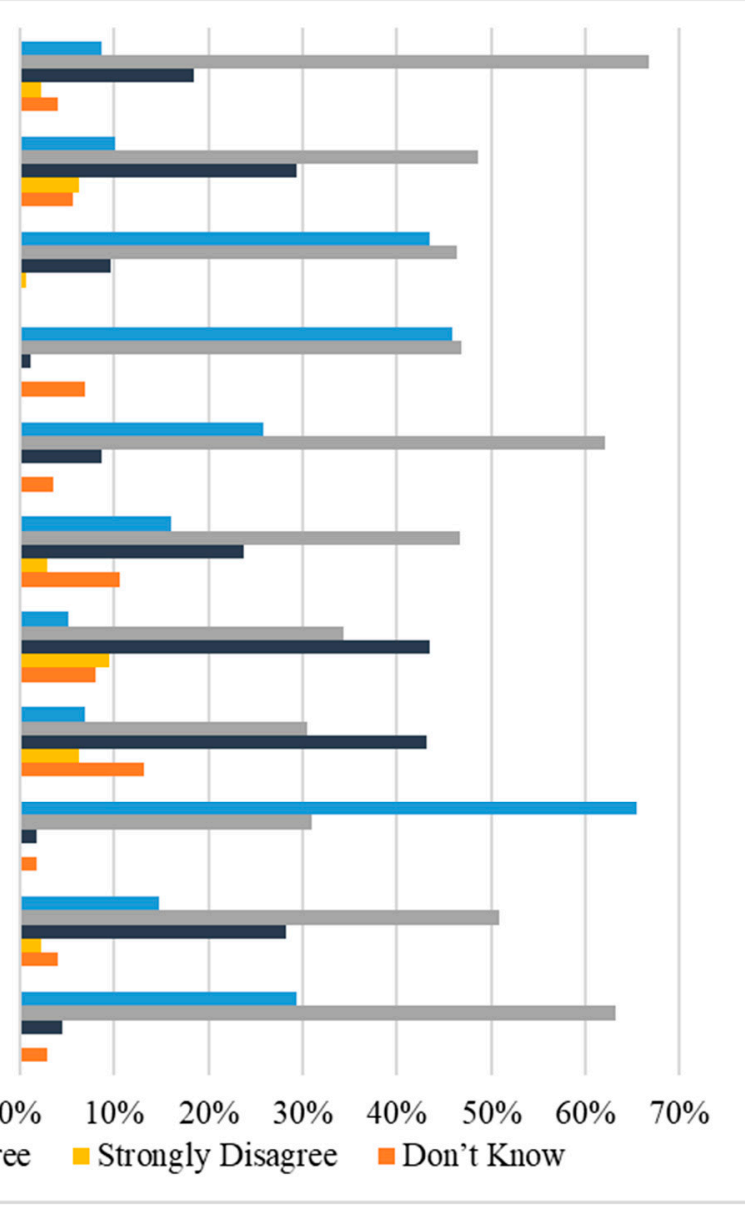

Figure 4. Dentists' attitudes toward oral cancer examination $(n=177)$.

\subsection{Clinical Practice Regarding Oral Cancer}

When evaluating clinical practice, a majority of dentists were familiar with the proper physical oral examination steps (182 dentists, $72.3 \%$ ). Moreover, $96 \%$ of dentists said that when taking a patient's medical history, they ask about current tobacco use, $89.2 \%$ said they ask about previous tobacco use, and $80 \%$ reported asking about the type and amount of tobacco used. To a lower extent, dentists reported asking patients about their current alcohol use (68\%), past alcohol use $(64.7 \%)$, and type and amount of alcohol used $(46.8 \%)$. Dentists also reported asking about their patients' history of cancer $(86.8 \%)$ and family history of cancer $(80.6 \%)$. 
A high proportion of dentists (77.6\%) reported that they have no educational material on OC available for their patients. Thirty-two dentists (18.4\%) reported that they had brochures or pamphlets on OC available for their patients. Only three dentists $(1.7 \%)$ reported that they provide verbal education and instructions to their patients about OC.

\subsection{Assessments of Dentists' Personal Characteristics and Knowledge of Oral Cancer}

The ICC was measured to evaluate differences in scores for the knowledge of the clinical presentation of and risk factors for OC across the five practice setting. The ICC for knowledge of the clinical presentation of OC was 0.028 , and for the knowledge of risk factors of OC it was 0.084 . Thus $2.8 \%$ and $8.4 \%$ of the variance in these scores is due to differences between the practice settings.

The distribution of low, medium, and high knowledge of the clinical presentation of and risk factors for OC showed that dentists aged less than 39 years were more likely to have high knowledge of the clinical presentation of $\mathrm{OC}$ when compared with older participants (adjusted $\mathrm{Chi}^{2}=3.96$, degrees of freedom $[\mathrm{df}]=4, p$ value $=0.411$ ). Dentists with less than 10 years of experience tended to have high knowledge of the risk factors for $\mathrm{OC}$ when compared to dentists with more than 10 years of experience (Adjusted $\mathrm{Chi}^{2}=11.38, \mathrm{df}=4, p$ value $\left.=0.023\right)($ Table 3$)$.

Table 3. Association between dentists' personal characteristics and knowledge of the clinical presentation of and risk factors for oral cancer $(n=177)$.

\begin{tabular}{|c|c|c|c|c|c|c|c|c|}
\hline \multicolumn{5}{|c|}{ Knowledge of Clinical Presentation of Oral Cancer } & \multicolumn{4}{|c|}{ Knowledge of the Risk Factors for Oral Cancer } \\
\hline & $\begin{array}{c}\text { Low } \\
\text { Score }(n)\end{array}$ & $\begin{array}{l}\text { Medium } \\
\text { Score }(n)\end{array}$ & $\begin{array}{c}\text { High } \\
\text { Score }(n)\end{array}$ & $p$ Value & $\begin{array}{c}\text { Low } \\
\text { Score }(n)\end{array}$ & $\begin{array}{l}\text { Medium } \\
\text { Score }(n)\end{array}$ & $\begin{array}{c}\text { High } \\
\text { Score }(n)\end{array}$ & $p$ Value \\
\hline \multicolumn{9}{|l|}{ Sex } \\
\hline Male & 73 & 12 & 7 & & 32 & 35 & 25 & \\
\hline Female & 65 & 16 & 4 & $0.671^{\dagger}$ & 33 & 29 & 23 & $0.908^{\dagger}$ \\
\hline \multicolumn{9}{|l|}{ Age (years) } \\
\hline$\leq 39$ & 71 & 11 & 9 & & 32 & 33 & 26 & \\
\hline $40-49$ & 45 & 11 & 0 & & 24 & 19 & 13 & \\
\hline$\geq 50$ & 20 & 6 & 2 & $0.411^{\dagger}$ & 7 & 12 & 9 & $0.603^{\dagger}$ \\
\hline \multicolumn{9}{|l|}{$\begin{array}{c}\text { Practical Experience } \\
\text { (years) }\end{array}$} \\
\hline$\leq 10$ & 25 & 7 & 4 & & 9 & 11 & 16 & \\
\hline $11-15$ & 39 & 6 & 3 & & 21 & 13 & 14 & \\
\hline$>15$ & 71 & 15 & 4 & $0.579^{\dagger}$ & 33 & 40 & 17 & $0.023^{+}$ \\
\hline \multicolumn{9}{|l|}{ Scope of Practice } \\
\hline General Practice & 84 & 14 & 4 & & 31 & 46 & 25 & \\
\hline Specialty Practice & 51 & 14 & 7 & $0.825^{+}$ & 32 & 18 & 22 & $0.698^{+}$ \\
\hline \multicolumn{9}{|l|}{$\begin{array}{l}\text { Last CPD Course on } \\
\text { Oral Cancer Attended }\end{array}$} \\
\hline$<2$ years ago & 48 & 10 & 4 & & 20 & 26 & 16 & \\
\hline $2-5$ years ago & 26 & 10 & 3 & & 14 & 12 & 13 & \\
\hline$>5$ years ago & 41 & 5 & 4 & & 23 & 12 & 15 & \\
\hline Never & 23 & 3 & 0 & $0.912^{\dagger}$ & 8 & 14 & 4 & $0.736^{+}$ \\
\hline
\end{tabular}

Cluster-adjusted univariate logistic analysis showed that dentists with less than 10 years of experience were 1.64 times more likely to have satisfactory knowledge of the clinical presentation of OC when compared to dentists with more than 15 years of experience. Also, dentists with less than 10 years of experience were 1.73 times more likely to have satisfactory knowledge of the risk factors for OC when compared to dentists with more than 15 years of experience, after adjusting for a clustering effect (Table 4). This significant association was not observed after applying the adjusted $\mathrm{Chi}^{2}$ test in Table 3; this is explained by the small sample size and the amended categorization of the study outcomes. The odds for dentists in specialty practice to have satisfactory knowledge of the clinical presentation of OC was 1.92 times that of dentists in general practice. The opposite was observed for knowledge about the risk factors for OC, with dentists in specialty practice being $46 \%$ less likely to have satisfactory knowledge. Dentists who attended a CPD course on OC within the past 2 years were 
2.23 times more likely to have satisfactory knowledge of the clinical presentation of OC. No significant association was identified between attending CPD courses and knowledge of the risk factors for OC (Table 4).

Table 4. Univariate logistic analysis of the likelihood of having a satisfactory knowledge of oral cancer $(n=177)$.

\begin{tabular}{|c|c|c|c|c|c|c|}
\hline \multicolumn{4}{|c|}{ Knowledge of the Clinical Presentation of Oral Cancer * } & \multicolumn{3}{|c|}{ Knowledge of the Risk Factors for Oral Cancer * } \\
\hline Characteristics & OR $\ddagger$ & $95 \%$ CI & $p$ Value & OR $\ddagger$ & $95 \%$ CI & $p$ Value \\
\hline \multicolumn{7}{|l|}{ Sex } \\
\hline Male & 1.00 & - & & 1.00 & - & \\
\hline Female & 1.18 & $0.73-1.89$ & 0.485 & 0.84 & $0.57-1.23$ & 0.375 \\
\hline \multicolumn{7}{|c|}{ Practical Experience (years) } \\
\hline$>15$ years & 1.00 & - & & 1.00 & - & \\
\hline $11-15$ years & 0.86 & $0.19-3.78$ & & 0.744 & $0.41-1.33$ & \\
\hline$\leq 10$ years & 1.64 & $1.32-2.04$ & 0.017 & 1.73 & $0.72-4.13$ & 0.355 \\
\hline \multicolumn{7}{|l|}{ Scope of Practice } \\
\hline General & 1.00 & - & & 1.00 & - & \\
\hline Specialty & 1.92 & $0.91-4.03$ & 0.084 & 0.54 & $0.22-1.33$ & 0.184 \\
\hline \multicolumn{7}{|c|}{$\begin{array}{c}\text { Last CPD Course on Oral } \\
\text { Cancer Attended }\end{array}$} \\
\hline Never & 1.00 & - & & 1.00 & - & \\
\hline$>5$ years ago & 1.68 & $0.50-5.57$ & & 0.52 & $0.24-1.11$ & \\
\hline $2-5$ years ago & 3.83 & $0.82-17.8$ & & 0.79 & $0.30-2.06$ & \\
\hline$<2$ years & 2.23 & $0.40-12.3$ & 0.321 & 0.93 & $0.57-1.51$ & 0.329 \\
\hline
\end{tabular}

${ }^{*}$ Binary outcome (satisfactory vs. unsatisfactory knowledge). ${ }^{\ddagger}$ Adjusted odds of satisfactory knowledge, accounting for clustering. OR: odds ratio, CI: confidence interval, CPD: continuous professional development.

\section{Discussion}

A patient's visit to the dentist is an opportunity for a comprehensive oral examination and a chance for one-on-one oral health education for the patients. The number of OC patients in Qatar has been increasing as the population has increased [4]. Qatar has a unique population structure with diverse ethnic origins, and these ethnic differences have been linked to the adoption of different health behaviors [14]. Qatar has universal healthcare coverage through the established governmental healthcare system, as all residents in the country are covered by the HMC and PHCC. Healthcare providers, and dentists in particular, play an important role in patient awareness and early detection of OC. This requires knowledge about the clinical presentation of and risk factors for OC.

In dental practice, extra- and intra-oral examination is an essential step in the examination of a new patient [15]. In our study, a high percentage of dentists, higher than percentages observed in other studies, correctly identified the importance of lymph nodes in metastatic cancer $[6,8]$. This was reflected in their attitude, as most dentists agreed that they were comfortable palpating patients' necks for a lymph node examination. An intra-oral examination includes a comprehensive examination of the oral cavity and the tongue. In our study, a large percentage of dentists demonstrated knowledge about the specific steps of oral and tongue examinations. However, a low percentage of dentists were confident in performing OC examinations. Moreover, only $48.6 \%$ of dentists felt that they had been adequately trained for this. Therefore, it is important that they receive regular training to refresh their basic knowledge and improve their oral and tongue examination skills. This could increase their confidence, and lead to a more positive attitude toward comprehensive oral examinations for their patients.

A high percentage of our dentists correctly recognized squamous cell carcinoma as the most common form of OC, which is similar to the percentage observed among dentists in Yemen, Kuwait, and North Carolina $[7,10,16]$. However, some important gaps in knowledge about the clinical features of OC were identified. Less than one-quarter $(21 \%)$ of dentists correctly replied that OC is asymptomatic in its early stages, which is lower than what has been reported in Iran (45\%) and British Columbia and Nova Scotia (78\%) [6,8]. Accordingly, a low proportion of dentists $(39 \%)$ replied that OC is mainly diagnosed at advanced stages, which is lower than what was observed in Kuwait (75\%) and Yemen 
$(66 \%)[10,16]$. Almost half of the dentists $(53.7 \%)$ were familiar with erythroplakia and leukoplakia as important signs of a premalignant lesion, but among them only 44 dentists (24\%) correctly identified erythroplakia as a more serious premalignant condition. Similarly, in Iran, 50\% of dentists correctly identified these signs. On the other hand, a higher percentage of dentists in Turkey (64.1\%) and Kuwait $(93 \%)$ correctly identified erythroplakia and leukoplakia as premalignant signs [10,17]. These are important signs of premalignancy that dentists need to know. The wide range in the level of dentists' knowledge by the country of practice might be related to different educational backgrounds, different training opportunities, and different shared educational environments, considering the differences in the study periods. The gaps we identified in clinical and diagnostic knowledge of OC need to be addressed through CPD courses.

A high percentage of dentists correctly identified tobacco, alcohol, and prior OC as risks for OC, which is consistent with other studies $[6,16,18]$. This was reflected in their practice of talking to patients about their medical history, as a majority of dentists properly assessed patients' present tobacco use, history of cancer, and, to a lower extent, patients' present alcohol use. Knowledge of the effect of chewing betel quid was poor, as almost half of the dentists did not know that Gutka use is a risk factor for OC. More emphasis is needed to increase their knowledge about the risk of different types of tobacco use, including smokeless tobacco use, which is widespread in Asian cultures. A high proportion of dentists believe that they should be trained to provide tobacco cessation education. Their knowledge that squamous cell carcinoma is directly linked to tobacco use showed their willingness to be actively involved in smoking cessation intervention.

Dentists had some problems distinguishing between risk factors and non-risk factors for OC. Therefore, more emphasis on the risk factors and non-risk factors for OC is needed in CPD courses. Increasing dentists' knowledge of these factors would help to raise population awareness and play an important role in OC prevention.

In the present study, nearly one-third of dentists had low knowledge of both the clinical presentation of and risk factors for OC. Moreover, $78 \%$ had low knowledge of the clinical presentation of OC. This is surprisingly more than what was observed in Clovis et al. (35\%), Patton et al. (59\%), and in Maryland (35.5\%) $[7,8,18]$. Although $66.7 \%$ of our study participants reported that their knowledge of OC was current, this was not reflected in their level of knowledge on the clinical presentation of OC, indicating the need for educational intervention in Qatar.

Dentists who had attended a CPD course on OC within the past 2 years were two times more likely to have satisfactory knowledge of the clinical presentation of OC. Although this association did not reach statistical significance, it was consistent with previous studies, in which attending a CPD course on OC significantly translated into better OC examination practices, better knowledge of the risk factors for OC among patients, and a higher level of clinical knowledge $[19,20]$. Furthermore, we observed no association between attending a CPD course and the level of knowledge on risk factors. This suggests that OC risk factors are not well addressed in the delivered courses, and that the focus is instead directed toward clinical knowledge. This is consistent with the results of Yellowitz et al., who showed that attending a CPD course on OC is not significantly associated with knowledge of the risk factors for OC [20]. This demonstrates that more emphasis is needed on the techniques used to deliver CPD courses and the importance of blended techniques of learning and education. CPD is regulated by Qatar Council for Health Care Practitioners (QCHP), and is compulsory for all healthcare practitioners in Qatar. Practicing dentists are expected to do $40 \mathrm{~h}$ of CPD every two years as a requirement for a practicing licensing renewal. However, it does not restrain part of the $40 \mathrm{~h}$ of $\mathrm{CPD}$ on a specific topic. Regarding the impact of years of experience, dentists with less than 10 years of experience were more likely to have high knowledge of the clinical presentation of and the risk factors for OC, compared to dentists with more than 15 years of experience, which is consistent with other studies $[7,18]$. Undergraduate studies have a positive impact on the level of knowledge, but this impact diminishes with time, reiterating the importance of CPD courses to update information. Currently, oral cancer screening in Qatar is not a separate reimbursement procedure [21]. It is part of 
the regular oral examination of patients. Qatar achieved universal coverage through the established governmental healthcare system, as all residents are covered with governmental health insurance in HMC and PHCC, including the oral examination procedure. However, a separate OC screening reimbursed procedure would improve the screening rate [22].

The strength of this study is represented by its methods. We used a paper-based, self-administered questionnaire to make it easy for participants to complete. Although this method is more costly and time consuming, we believe that it overcomes the accessibility barriers of our target population. The other strength of this study is the acceptable response rate of $65.31 \%$, which is explained by the strategy we used to maximize response, including initial invitation well in advance of the study, followed by multiple additional invitations to non-responders.

Non-response bias is one of the limitations of this study. Indeed, non-respondents to this survey might have a different level of knowledge than respondents. However, there was a high proportion of respondents from the PHCC, and we believe there is no difference between the respondents and non-respondents from the PHCC. In the HMC, the response among dentists was poor, and thus respondents might be different than non-respondents. Another limitation is that dentists practicing in the private sector were not included; therefore, our results cannot be generalized to the private sector.

\section{Conclusions}

Assessing dentists' knowledge is one way to measure their performance. This study identified gaps in knowledge among dentists practicing in the governmental health sector, which strongly suggested that dentists in Qatar could benefit from educational interventions (i.e., CPD courses) about the main clinical features of $\mathrm{OC}$ and the evidence-based risk factors. Our results showed that dentists with less than 10 years of practical experience had high knowledge of OC, thus one solution could be for dentists who have recently completed their undergraduate studies to get involved and share their knowledge by providing lectures or educational courses to colleagues in their practice settings. Dental offices are also a unique setting in which cost-effective tobacco cessation intervention could be provided. However, we recommend further research on the applicability of this type of intervention and the readiness of dentists to provide it. The results of this study can be used as baseline data for future CPD courses on OC for dentists and could help evaluate the effectiveness of such courses in raising dentists' knowledge and awareness. Moreover, the study results can be used to plan future $\mathrm{CPD}$ courses aimed at improving the delivery of care in the health system.

Author Contributions: Conceptualization, D.H.J., U.N. and M.S.A.-D.; methodology, D.H.J., U.N. and M.S.A.-D.; software, D.H.J.; validation, D.H.J., U.N.; formal analysis, D.H.J.; investigation, D.H.J. and U.N.; resources, D.H.J.; data curation, D.H.J.; writing-original draft preparation, D.H.J.; writing-review and editing, D.H.J. and U.N.; visualization, D.H.J. and U.N.; supervision, U.N. and M.S.A.-D.; project administration, D.H.J.; funding acquisition, U.N.

Funding: This work has been funded by Qatar university.

Acknowledgments: This research was supported by a student grant QUST-1-CHS-2018-13 from the Qatar University Office of Research Support. My gratitude goes to Hanan Abdul Rahim, Head of the Department of Public Health College of Health Sciences, for her guidance; Asmaa AlKhatib, Manager of the Oral Health Division of the PHCC, and Khouloud Zidan for their help during data collection; and all the dentists who participated in this survey.

Conflicts of Interest: The authors declare no conflicts of interest. 
Appendix A
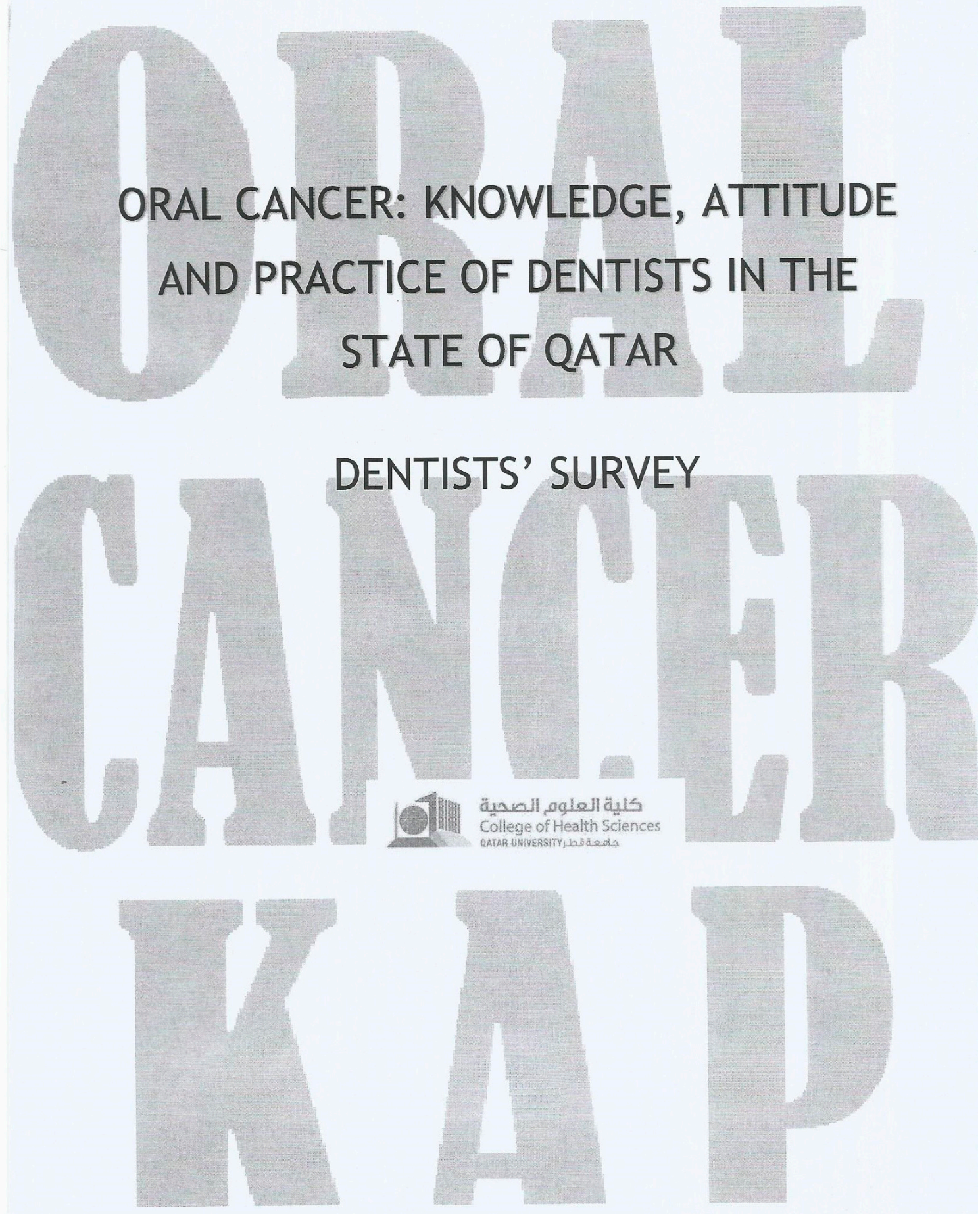

Figure A1. Cont. 


\section{Informed consent}

This research is carried out to assess Oral Cancer knowledge, attitude and practice among dentists in the state of Qatar. Oral cancer is an important oral health issue that needs to call attention to. This survey will help to assess your level of knowledge about oral cancer. Explore your opinions and attitude toward oral cancer prevention and examination. Identify your current clinical practice toward oral cancer examination. This would help for future planning on oral cancer screening programs and improve the health system delivery of care

You are invited to participate in this self-administered survey. The questionnaire takes approximately 10 minutes to be completed. Your anonymity is assured as you will not be asked for you name or identifying information. All information will be treated with utmost confidentiality. Data will be stored in the researcher's laptop with password protected files and will be accessible only to the authorized investigators. Your participation is voluntary, and you may refuse to participate. You will receive no direct benefit nor risks from participating in this research.

If you have any question about the survey or the study, you can contact:

\section{Dr. Diana Jboor \\ mobile number 50182901}

e-mail di1600061@qu.edu.ca

Please select your choice:

I have read the above information and I voluntarily agree to participate in the study.

I have read the above information and I refuse/ disagree to participate in the study.

Figure A1. Cont. 
Oral Cancer: Knowledge, Attitude and Practice of Dentists in the State of Qatar DENTISTS' SURVEY

Please read each question carefully and provide your most appropriate response.

\section{Dental Practice}

1. Which of the following best describes your PRACTICE setting?

1. HMC Hospital

$\square$ 2. Primary Health Care Center

2. When doing an oral examination, the clinician should: (CHECK ONLY ONE)

$\square$ 1. Palpate the thyroid gland

$\square$ 2. Palpate the lymph nodes of the head and neck

$\square$ 3. Palpate all salivary glands

$\square$ 4. Radiograph suspected lesions

$\square$ 5. All of the above

3. When examining the tongue for oral cancer, the clinician should: (CHECK ONLY ONE)

$\square \quad$ 1. Have patient stick out tongue as far as possible for inspection

$\square$ 2. Examine posterior dorsum of the tongue with a tongue blade or mirror

$\square$ 3. Pull the patient's tongue out and inspect both sides of it

$\square$ 4. Inspect the underside of the tongue by

- having the patient raise tongue

5. All of the above

$\square$ 6. Don't know

4. When you detect a lesion, do you: (CHECK ONE OR MORE)

1. Perform Toluidine Blue Staining

2. Perform Brush Biopsy

3. Perform Incisional Biopsy

4. Use ViziLite

5. Refer

6. Other (Specify)
5. In the past 12 months, about how many patients did you biopsy for suspicious oral lesions?

Write in number; if none, write "0."

6. In the past 12 months, about how many patients did you refer for diagnosis of suspicious oral lesions? Write in number; if none, write " $0 . "$

7. In your opinion, who should have the primary role in detecting early signs and symptoms of oral cancer?

$\square \quad$ 1. General Dentist

$\square$ 2. Oral and maxillofacial surgeon

$\square$ 3. Dermatologist

$\square$ 4. Ear, nose and throat specialist

$\square$ 5. Other (Specify)

8. What kind of oral cancer patient education materials are available in your practice?

$$
\text { 1. None }
$$

$\square \quad$ 2. Brochures / Pamphlets

$\square \quad 3$. Video

4. Other (Explain)

9. When taking a medical history, which of the following do you assess?

(CIRCLE ONE ON EACH LINE)

Patient's past alcohol use?

Patient's present alcohol use?

Type \& amount of alcohol used?

Patient's previous tobacco use?

Patient's present tobacco use?

Type \& amount of tobacco?

Patient's history of cancer?

Family history of cancer? 
ANSWER THE FOLLOWING BASED ON YOUR KNOWLEDGE ABOUT

\section{ORAL CANCER}

10. Excluding the lip, which of the following are the TWO most common sites of oral cancer? (CHECK TWO)
1. Soft palate
3. Tongue
3. Gingiva
4. Buccal mucosa
5. Floor of mouth
6. Don't know

11. The most common form of oral cancer is: (CHECK ONLY ONE)
1. Lymphoma
2. Squamous cell carcinoma
3. Basal cell carcinoma
4. Adenocarcinoma
5. Kaposi's sarcoma
6. Don't know

12. Which ONE of the following factors is LEAST likely to be associated with oral cancer: (CHECK ONLY ONE)
1. Increasing age
2. Familial clustering
3. Alcohol consumption
4. Tobacco use
5. Don't know

13. The symptom most commonly expressed by a patient with an EARLY sign of oral cancer is: (CHECK ONLY ONE)
$\square$ 1.Pain
$\square$ 2. Ulceration
$\square$ 3. Swelling
$\square$ 4. None; patient is asymptomatic
$\square$ 5. Don't know

14. The majority of oral cancers are diagnosed in people who are: (CHECK ONLY ONE)

$\square$ 1. Less than 18 years of age

$\square$ 2. 18 - 39 years of age

$\square 3.40$ - 59 years of age

$\square 4.60$ years of age or older

$\square$ 5. Don't know

15. A lymph node most characteristic of oral cancer metastasis, when palpated, is: (CHECK ONLY ONE)

$\square$ 1. Hard, painful, mobile

2. Hard, painless, mobile or fixed

3. Soft, painful, mobile

$\square$ 4. Soft, painless, fixed or mobile

$\square$ 5. Don't know

16. Which area of the tongue is most likely to develop oral cancer? (CHECK ONLY ONE)
$\square \quad$ 1. All the tongue
$\square$ 2. Dorsal surface
$\square$ 3. Ventral - lateral border
$\square$ 4. Anterior - lateral border
$\square \quad 5$. Base of tongue
$\square$ 6. None of the above
7. Don't know

17. Oral cancer lesions are most often diagnosed in which stage: (CHECK ONLY ONE)
$\square \quad$ 1. Premalignant
$\square$ 2. Early
$\square$ 3. Advanced
$\square$ 4. Don't know

18. Lip cancers: (CHECK ONLY ONE)
$\square$ 1. Are related to sun exposure
$\square$ 2. Are increasing each year
$\square$ 3. Have a worse prognosis than most oral cancers
$\square$ 4. Affect the upper lip more frequently than the lower lip
$\square$ 5. Have not been related to any form of tobacco use
$\square$ 6. Don't know

2

Figure A1. Cont. 
19. Early oral cancer lesions usually appear as a: (CHECK ONLY ONE)

$\square$ 1. Small, painless, red area

$\square$ 2. Small, painful, red area

$\square$ 3. Small, painful, white area

$\square$ 4. Small, bleeding area

$\square$ 5. Don't know

20. Of the following conditions, which TWO are most likely to be associated with oral cancer?

(RANK IN ORDER OF IMPORTANCE)

$\square$ 1. Leukoplakia

2. Erythroplakia

3. Pemphigus vulgaris

4. Migratory glossitis

5. Denture stomatitis

6. Don't know

RANK

IMPORTANCE

First

Second

(Write in

numbers)
21. Which of the following factors place an individual at high risk for oral cancers?

(CIRCLE YOUR RESPONSE ON EACH LINE)

\section{Older age}

Yes No Don't Know

Poor fitting dentures

Use of alcohol

Poor oral hygiene

Use of tobacco products

Use of spicy foods

Family history of cancer

Hot beverages and food

Low consumption of fruits

and vegetables

Use of marijuana

Certain viruses (i.e. HPV)

Obesity

Use of 'Gutka'

Chewing 'Beetle Quid'

Prior oral cancer lesion

Use of mouth rinses

$\begin{array}{lll}\square & \square & \square \\ \square & \square & \square \\ \square & \square & \square \\ \square & \square & \square \\ \square & \square & \square \\ \square & \square & \square \\ \square & \square & \square \\ \square & \square & \square \\ \square & \square & \square \\ \square & \square & \square \\ \square & \square & \square \\ \square & \square & \square \\ \square & \square & \square \\ \square & \square & \square \\ \square & \square & \square \\ \square & \square & \square\end{array}$

\section{OPINIONS}

22.Please indicate the extent to which you agree or disagree with each of the following statements: (CIRCLE ONE RESPONSE ON EACH LINE)

Strongly Agree Disagree Strongly Don't Agree $\quad$ Disagree Know

a) My knowledge about oral cancer is current.

b) Oral cancer examinations for those 40 years of age and older should be provided annually.

c) Oral cancer examinations for adults 18-39 years of age should be provided annually.

d) I am comfortable referring patients with suspicious oral lesions to specialists.

e) Oral cancer exams can be discontinued after 3 negative exams.

f) I am not confident in my ability to perform oral cancer exams.

g) Oral cancer examinations should be a separate reimbursable procedure.

h) I am comfortable palpating lymph nodes in the necks of patients.

i) Early detection improves 5-year survival rates from oral cancers.

j) Dentists should be trained to provide tobacco cessation education.

k) I am adequately trained to examine patients for oral cancer.

$\begin{array}{lllll}\square & \square & \square & \square & \square \\ \square & \square & \square & \square & \square \\ \square & \square & \square & \square & \square \\ \square & \square & \square & \square & \square \\ \square & \square & \square & \square & \square \\ \square & \square & \square & \square & \square \\ \square & \square & \square & \square & \square \\ \square & \square & \square & \square & \square \\ \square & \square & \square & \square & \square \\ \square & \square & \square & \square & \square \\ \square & \square & \square & \square & \square\end{array}$

3

Figure A1. Cont. 


\title{
Personal Data
}

\author{
23. Your Gender: $\square$ 1. Male \\ 26. Years of practical experience: (CHECK ONE) \\ $\square$ 2. Female \\ $\square$ 1. less than 5 years \\ $\square$ 2. $5-10$ years \\ $\square$ 3. $11-15$ years \\ 24. Your age: (CHECK ONE) \\ $\square$ 4. More than 15 years \\ $\square$ 1. $23-29$ years \\ $\square$ 2. $30-39$ years \\ 27. Which of the following best describe your \\ scope of practice? \\ $\square$ 3. $40-49$ years \\ 1. General dental practice \\ $\square$ 2. Speciality dental practice \\ $\square$ 4. 50 - 59 years \\ $\square$ 5. 60 years and older \\ 25. Year of graduation \\ from dental school (e.g. 2007): \\ 28. When was the last time you attended a \\ continuing education course on oral cancer? \\ (CHECK ONLY ONE) \\ $\square 1$. Within the past 2 years \\ $\square 2$. During the past $2-5$ years \\ $\square 3$. More than 5 years ago \\ $\square$ 4. Never \\ Thank you \\ We appreciate your cooperation and support for this \\ project \\ Please Return Promptly
}

Figure A1. The Study Questionnaire.

\section{References}

1. Ferlay, J.; Soerjomataram, I.; Dikshit, R.; Eser, S.; Mathers, C.; Rebelo, M.; Parkin, D.M.; Forman, D.; Bray, F. Cancer incidence and mortality worldwide: Sources, methods and major patterns in GLOBOCAN 2012. Int. J. Cancer 2015, 136, E359-E386. [CrossRef] [PubMed] 
2. Rikardsen, O.G.; Bjerkli, I.H.; Uhlin-Hansen, L.; Hadler-Olsen, E.; Steigen, S.E. Clinicopathological characteristics of oral squamous cell carcinoma in Northern Norway: A retrospective study. BMC Oral Health 2014, 14, 103. [CrossRef] [PubMed]

3. Brocklehurst, P.; Kujan, O.; Glenny, A.-M.; Oliver, R.; Sloan, P.; Ogden, G.; Shepherd, S. Screening programmes for the early detection and prevention of oral cancer. Cochrane Database Syst. Rev. 2010, 11. [CrossRef]

4. Ministry of Development Planning and Statistics, Sukkan Newsletter. Available online: https://www.mdps. gov.qa/en/statistics/Statistical\%20Releases/Population/Population/2017/Sukkan_38_En_Dec_2017.pdf (accessed on 23 April 2018).

5. Petersen, P.E. Oral cancer prevention and control-The approach of the World Health Organization. Oral Oncol. 2009, 45, 454-460. [CrossRef] [PubMed]

6. Razavi, S.M.; Zolfaghari, B.; Foroohandeh, M.; Doost, M.E.; Tahani, B. Dentists' knowledge, attitude, and practice regarding oral cancer in Iran. J. Cancer Educ. 2013, 28, 335-341. [CrossRef] [PubMed]

7. Patton, L.L.; Elter, J.R.; Southerland, J.H.; Strauss, R.P. Knowledge of oral cancer risk factors and diagnostic concepts among North Carolina dentists. Implications for diagnosis and referral. J. Am. Dent. Assoc. (1939) 2005, 136, 602-610. [CrossRef]

8. Clovis, J.B.; Horowitz, A.M.; Poel, D.H. Oral and pharyngeal cancer: Knowledge and opinions of dentists in British Columbia and Nova Scotia. J.-Can. Dent. Assoc. 2002, 68, 415-420. [PubMed]

9. Hassona, Y.; Scully, C.; Shahin, A.; Maayta, W.; Sawair, F. Factors Influencing Early Detection of Oral Cancer by Primary Health-Care Professionals. J. Cancer Educ. 2016, 31, 285-291. [CrossRef] [PubMed]

10. Joseph, B.K.; Sundaram, D.B.; Sharma, P. Oral cancer awareness among dentists in Kuwait. Med. Princ. Pract. 2012, 21, 164-170. [CrossRef] [PubMed]

11. Flynn, T.N. Design and Analysis of Cluster Randomization Trials in Health Research: Allan Donner and Neil Klar. London: Arnold, 2000, pp.178, £35.00. ISBN: 0-340-69153-0. Int. J. Epidemiol. 2001, 30, 407-408. [CrossRef]

12. Donner, A.; Klar, N. Design and Analysis of Cluster Randomization Trials in Health Research; Wiley: London, UK, 2010.

13. StataCorp. Stata Statistical Software: Release 15; StataCorp LLC: College Station, TX, USA, 2017.

14. Bulatao, R.A.; Anderson, N.B.; National Research Council. Understanding racial and Ethnic Differences in Health in Late Life: A Research Agenda; National Academies Press: Washington, DC, USA, 2004.

15. Weinberg, M.A.; Estefan, D.J. Assessing oral malignancies. Am. Fam. Physician 2002, 65, 1379-1387. [PubMed]

16. Alaizari, N.A.; Al-Maweri, S.A. Oral cancer: Knowledge, practices and opinions of dentists in Yemen. Asian Pac. J. Cancer Prev. 2014, 15, 5627-5631. [CrossRef] [PubMed]

17. Kebabcioğlu, Ö.; Pekiner, F.N. Assessing Oral Cancer Awareness Among Dentists. J. Cancer Educ. 2018, 33, 1020-1026. [CrossRef] [PubMed]

18. Canto, M.T.; Drury, T.F.; Horowitz, A.M. Maryland dentists' knowledge of oral cancer risk factors and diagnostic procedures. Health Promot. Pract. 2001, 2, 255-262. [CrossRef]

19. Horowitz, A.M.; Drury, T.F.; Goodman, H.S.; Yellowitz, J.A. Oral pharyngeal cancer prevention and early detection: dentists' opinions and practices. J. Am. Dent. Assoc. 2000, 131, 453-462. [CrossRef] [PubMed]

20. Yellowitz, J.A.; Horowitz, A.M.; Drury, T.F.; Goodman, H.S. Survey of us dentists'knowledge and opinions about oral pharyngeal cancer. J. Am. Dent. Assoc. 2000, 131, 653-661. [CrossRef] [PubMed]

21. Ministry of Public Health. Achieving Excellence in Cancer Care. Available online: https://www.moph.gov. qa/publications/Documents/Health\%20Publications/National\%20Cancer\%20Framework\%20English.pdf (accessed on 4 March 2019).

22. Halpern, M.T.; Romaire, M.A.; Haber, S.G.; Tangka, F.K.; Sabatino, S.A.; Howard, D.H. Impact of state-specific Medicaid reimbursement and eligibility policies on receipt of cancer screening. Cancer 2014, 120, 3016-3024. [CrossRef] [PubMed]

(C) 2019 by the authors. Licensee MDPI, Basel, Switzerland. This article is an open access article distributed under the terms and conditions of the Creative Commons Attribution (CC BY) license (http:/ / creativecommons.org/licenses/by/4.0/). 